\section{Review of stir casting technique and technical challenges for ceramic reinforcement particulate and aluminium matrix composites}

MALEK ALI - Faculty of Aviation Sciences, Amman Arab University, Jordan - malikali77@yahoo.com Érkezett: 2020. 03. 29. - Received: 29. 03. 2020. - https://doi.org/10.14382/epitoanyag-jsbcm.2020.32
Malek ALI

Educational Background: 2011, Ph.D. in Materials Engineering - University Science Malaysia (USM) Malaysia. Major: Nanotechnology. 2007, M.Sc. in Materials Engineering - University Science Malaysia (USM). 2000, B.Sc. in Materials Science- University of Technology, Iraq. Associate professor, Faculty of Aviation Sciences, Amman Arab University. Research experience in the following areas: Synthesis Advanced Nanomaterials. Metallurgy, Nano. Composites (Polymer, Ceramics, Metals), Corrosion and Energy. Manufacturing/Fabrication of Metallic.

\begin{abstract}
Ceramic metal composites are promising advanced materials compared to conventional materials due to special properties such as: low weight, low cost, wear resistance, corrosion resistance, and high strength, etc. Stir casting is one of the lowest costs and simplest ways of making aluminium matrix composites. The main limitations of stir casting are poor distribution with combination of the reinforcement ceramic particles (agglomerations) in the metal matrix, porosities in composites during fabrication, and wettability of ceramic particles with molten metal's. Enhancement of stir casting parameters for Ceramic-Metals Matrix Composites (CMMCs) is the main objective for many studies. In this paper, the stir casting process will be discussed in detail with parameters affecting the homogeneous distribution of reinforcements, porosities in composites during fabrication, and the mechanical properties of the ceramic metal matrix composites.
\end{abstract}

Keywords: stir casting, ceramic reinforcement, aluminium matrix composites

Kulcsszavak: keveréses öntés, kerámia megerôsítés, aluminium matrix kompozitok

\section{Introduction}

A composite material can be defined as a combination of the best properties of each of the component materials; each material retains its separate chemical, physical, and mechanical properties. The three major composites are: ceramic matrix composite (CMMC), metal matrix composite (MMC), and polymer matrix composite (PMC). The three composites have a different properties and production methods that portrays specific behavior and capabilities. The main advantages of composite materials are their high strength and stiffness, combined with low density, fatigue life, and high corrosion resistance. The reinforcing stage provides the strength and stiffness. In most cases, the reinforcement is harder, stronger, and stiffer than the matrix. The reinforcement is usually a fiber or a particulate with regular or irregular shape. Particulate reinforced composites usually contain less reinforcement (up to 40 to 50 volume percent) due to processing difficulties and brittleness [1]. There are several fabrication techniques available in manufacturing the CMMC materials. Fabrication methods can be divided into three types. These are solid phase processes, liquid phase process, and semi-solid fabrication process. Liquid phase process includes stir casting, liquid metal infiltration, squeeze casting, and spray code position $[2,3]$. Ceramics particles are good candidate as reinforcement materials such as oxides, carbides, and nitrides which are characterized by their strength and stiffness at ambient and elevated temperature. Choosing the manufacturing process for any MMCs is based on several factors such as the: maintenance of reinforcement strength, minimization of reinforcement damage, promotion of wetting and bonding between the matrix and reinforcement, ability to achieve the spacing and orientation of reinforcement with the matrix, and cost. With these several fabrication techniques, there are however problems associated with homogeneous distribution of reinforcement, and porosity in composites during fabrication, essential for optimum mechanical properties of MMC [4-10]. Literature survey indicate that various parameters of stir casting process such as: stirring speed and time, stirring blade angle, pouring temperature and solidification rate, reinforcement's percentage and size have major effect on fabrication of MMC. Enhancement of parameters of stir casting process for CMC is the main objective for many studies. Few of these works are concerned with parameters that are affected by homogeneous distribution of reinforcement, and porosities in composites during fabrication which are the essential for optimum mechanical properties of MMC [11].

\section{Stir casting}

Stir casting is currently the most popular commercial method of producing aluminum-based composites. Stir casting of MMCs was initiated in 1968 [12,13]. In this process, powder form as reinforcing phases are usually distributed into molten metal's by mechanical stirring as shown in Fig. 1. Non-uniform distribution, and porosity in casted CMMCs consider main disadvantages for stir casting process. Generally, the difference in density is between the liquid metal and the reinforcement and the consequent tendency to reinforce the sink or float, resulting in nonuniform distribution of the reinforcement in the solidified composite. 


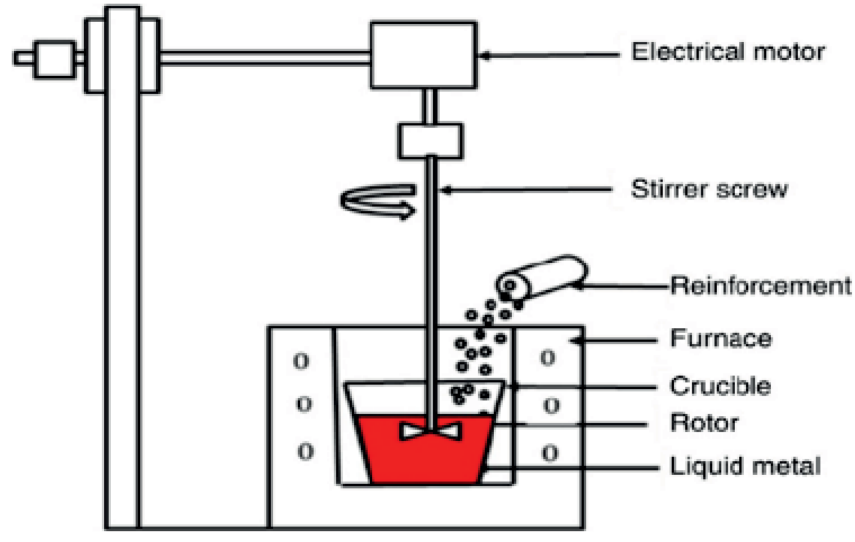

Fig. 1 Mechanical stirring

1. ábra Mechanikus keverés

\section{Effect of stirring speed and time on}

\section{distribution of particles and porosities in casted CMMCs}

For most applications, a homogeneous distribution of the particles is desirable in order to maximize the mechanical properties. Prabu et al. [14] reported by microstructure analysis that during lower speed and lower stir time particle clustering occurred in some places, and some places were identified without $\mathrm{SiC}$ inclusion. By increasing the stirring speed and stirring time better homogeneous distribution of $\mathrm{SiC}$ in the $\mathrm{Al}$ matrix were found. Better distributions of $\mathrm{SiC}$ were found at $600 \mathrm{rpm}$ and $10 \mathrm{~min}$ stirring time condition as shown in Fig. 2.
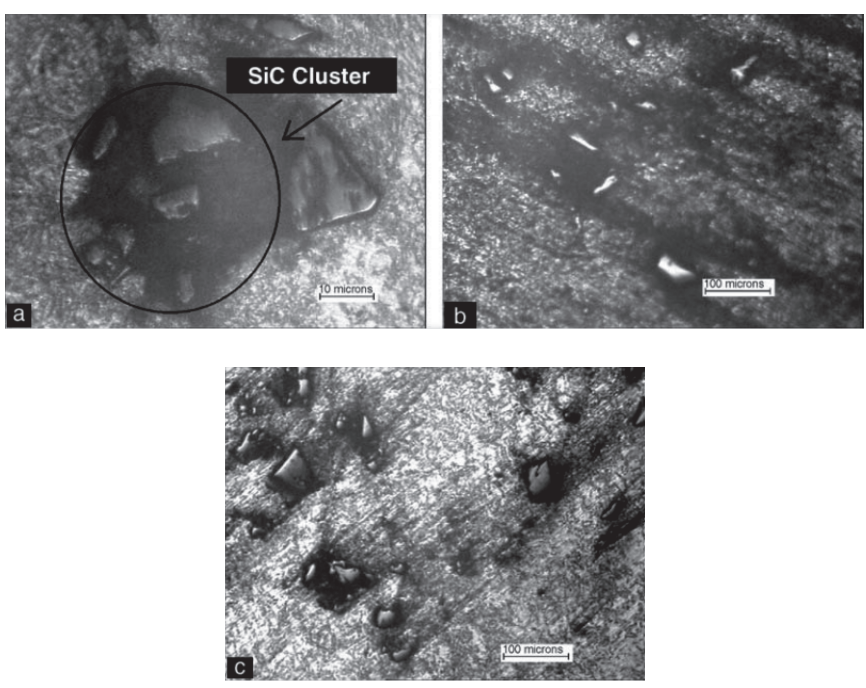

Fig. 2 Microstructure of Al-10\%SiCp MMC fabricated at $600 \mathrm{rpm}:$ (a) $5 \mathrm{~min}$ stirring; (b) 10 min stirring; (c) 15 min stirring

2. ábra 600 fordulat/perc sebességen készitett Al-10\%SiCp MMC mikroszerkezete: (a) 5 perc keverés után; (b) 10 perc keverés után; (c) 15 perc keverés után

Also, they reported that with higher speeds (700 rpm), more porosity has been observed in the microstructure which lead to minimize the mechanical properties. From Fig. 3 Adetayo et al. [15] explained the influence of stirring speed on stir casting synthesis of $15 \mathrm{wt} \%$ silicon carbide particle reinforced aluminium alloy (SiCp-6061 Al) composite.
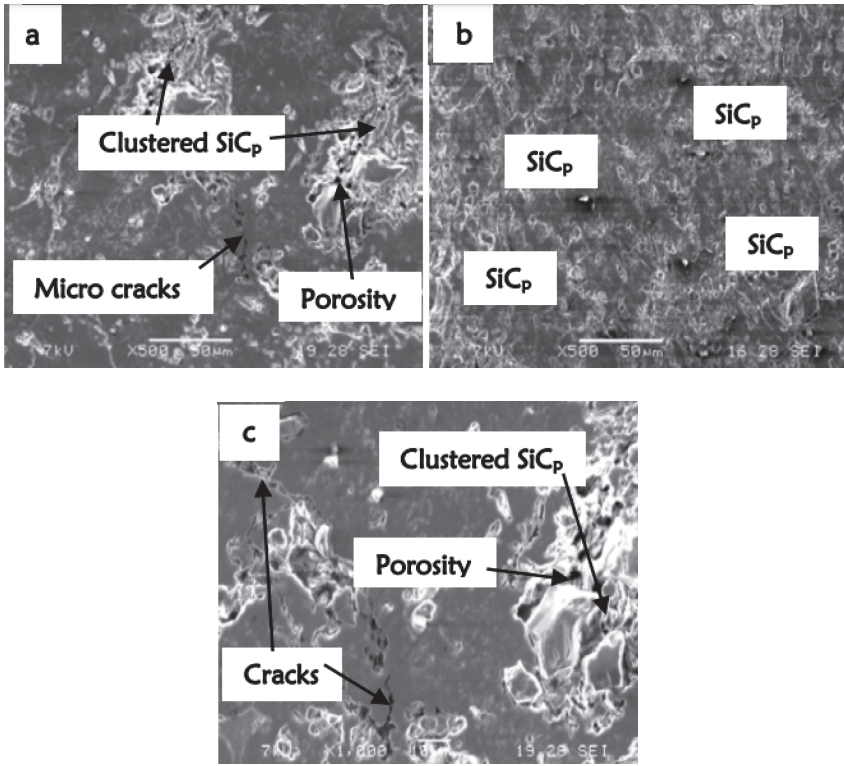

Fig. 3 Microstructure of 15 wt\% SiCp Al composite processed at (a) $300 \mathrm{rpm}$ (b) 500 rpm and (c) $700 \mathrm{rpm}$. The formation of composites, porosity, and micro cracks are indicated

3. ábra 15 wt\% SiCp Al kompozit mikroszerkezete különbözö fordulatszám esetén: (a) 300 (b) 500 és (c) 700 fordulat/perc. A kompozitok kialakulásának, repedéseknek és pórusok helye az ábrán jelezve

They reported that at $300 \mathrm{rpm}$, it is observed from the micrograph that regions of clustering and micro porosity are detected. Moreover, the distribution of $\mathrm{SiC}$ is not uniformly dispersed. This indicates that $300 \mathrm{rpm}$ is insufficient to achieve homogenous distribution of $\mathrm{SiCp}$ in the $\mathrm{Al}$ alloy matrix. With higher stirring speed of $500 \mathrm{rpm}$, an improved distribution of the SiCp is achieved. Moreover, vortex formation is found to be minimized at $500 \mathrm{rpm}$ stirring speed thereby stabilizing centrifugation which may lead to minimal stirring efficiency and potentially severe air entrainment at higher stirring condition. At higher stirring speed of $700 \mathrm{rpm}$, the porosity in the microstructure is more pronounced. This condition is attributed to the vigorous vortex formation due to high stirring speed which enables oxide skins, gases and contaminants to be entrained in the melt. Furthermore, the distribution of the $\mathrm{SiCp}$ is not effective enough due to the formation of undesirable conditions such as large porosity and gas entrapment. Also, Aqida et al. [16] explained that low rpm of the stirrer applies less shearing force on the matrix metal and there is no space for the reinforcement particles (dispersed phase) to distribute uniformly throughout the matrix. Moreover, the dispersed phase has the tendency to agglomerate and form clusters. This happens due to the absence of the required force to resist it. At higher speeds of the stirrer the shearing force applied on the matrix metal is higher which creates the passage for the dispersed phase to move inside through the vortex created by stirring. The energy supplied by high speed rotation of the stirrer is strong enough to disperse the particles of the dispersed phase which causes uniform distribution of the dispersed phase into the matrix. It was also founded out by the researchers that on increased stirrer speeds there is chance for the gas particles to move inside the matrix and increase the porosity [16]. Hashim et al. [17] reported that it has also been indicated that the reinforcement particles occupy inter dendritic and secondary 
dendrite arm spacing; therefore, the finer the spacing or the finer the matrix grain size, the better is the particle distribution. Also, the processing temperature effects the viscosity of the melt. The particle distribution is subjective to the viscosity change. So, the stirring speed is considered as a crucial factor in the fabrication of MMCs. The stirring action should be slow to prevent the formation of vortex at the surface of the melt, and care must be taken not to break the surface too often, which could contaminate the bath with dross. Use of a slowly rotating, propeller like mechanical stirrer is preferred by some foundries. In fact, results of laboratory studies indicate that the mechanical property of the casting are maximized by continuous stirring versus intermittent (hand) stirring. When induction melting, the furnace's natural eddy current stirring action usually is sufficient to disperse the particles, although supplementary hand stirring (with the power off) also is recommended to ensure that no particles have congregated in potential "dead" zones [18]. According to R. S. Rana et al. [19] porosity is a casting defect and is undesirable as far as Aluminium matrix composite castings are concerned. However, the process parameters of holding times, stirring speed, and the position of the impeller affect the development of porosity. It has also been reported by Vaibhav Ingle et al. [20] that the structural defects during casting like porosity are a result of unsatisfactory casting technology. Hashimet et al. [21] reported that the occurrence of porosity cannot be ruled out however, it can definitely be minimized. Porosity formation is caused by:

i. Gas entrapment during vigorous stirring,

ii. Air bubbles entering the slurry either independently or as an air envelope to the reinforcement particles,

iii. Water vapor $\left(\mathrm{H}_{2} \mathrm{O}\right)$ on the surface of the particles,

iv. Hydrogen evolution, and

v. Shrinkage during solidification.

Generally, this non uniformity and porosity are generated due to, difference in density between the liquid metal and the reinforcement, oxide skins, and formation of gases. Therefore, and optimum stirring speed and time are required in order to achieve uniform distribution in the matrix with less porosity. Also uniform distribution in the matrix with less porosity can be improved by: keep the viscosity within the allowed limit, alloys with minimum reactivity to the reinforcement must be used, covering the melt with an inert gas atmosphere to reduce the oxidation, giving heat treatment to the reinforcement particles to remove gas layer around the particle surface which impedes wetting between the particles and molten metal's, and stirring of the melt to minimize the settling of particles due to density difference [22-25]. Based on the studies highlighted, the stirring speed is recognized as an important process parameter for processing aluminum composite [26-29].

\section{Effect of stirring blade number with angle on distribution of particles and porosities in casted CMMCs}

The blade angle (Fig. 4) and number of blades are prominent factor which formed the vortex by the stirring on solid-liquid mixing to transfers reinforcements particles into the melt from the liquid surface and lead to uniform distribution. Therefore, selection of a suitable blade angle, and numbers of blades are crucial to acquire good level of axial flow and shearing action [30].

(a)

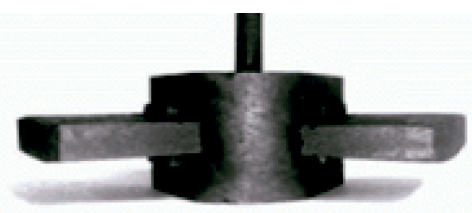

( b )

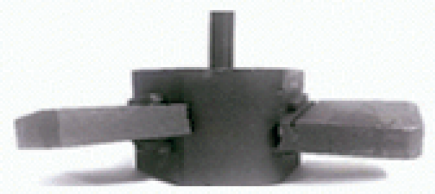

c )

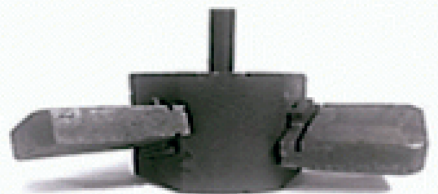

(d)

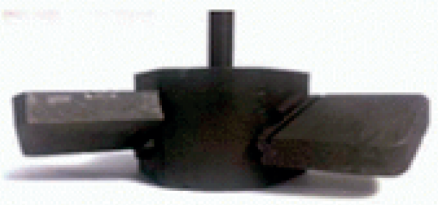

(e )

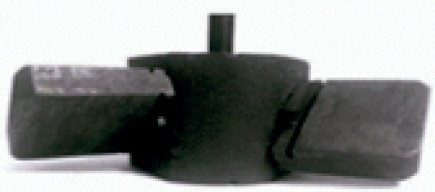

(f)

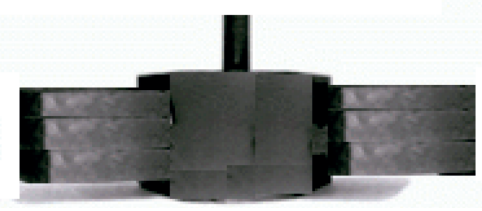

Fig. 4 Three blades stirrer, showing different blade angles (a) $0^{\circ}$, (b) $30^{\circ}$, (c) $45^{\circ}$, (d) $60^{\circ}$, (e) $75^{\circ}$, and (f) $90^{\circ}$

4. ábra Három pengés keverők, kiemelve azok különbözö penge dőlési szögét: (a) $0^{\circ}$, (b) $30^{\circ}$, (c) $45^{\circ}$, (d) $60^{\circ}$, (e) $75^{\circ}$ és (f) $90^{\circ}$

To investigate the effect of blade angle, researchers used water model and CFD model. They selected blade angle as 15 , $30,45,60$ and $90^{\circ}$. In a water model Ravi et al. [31] investigated the effect of impeller blade angle over the distribution of solid particles in the liquid. They found at low angle $\left(\alpha=15^{\circ}\right)$ particles are dispersed below the stirrer. Impeller with blade angle $\left(\alpha=30^{\circ}\right)$ performed well and shows uniform dispersion without concentration of particles. Whereas, impeller with high blade angle $\left(\alpha>30^{\circ}\right)$, most of the solid particles concentrate at just below the tip of the impeller blade which results more radial variation. Thus, $30^{\circ}$ was concluded as optimal value of blade angle with respect to stirrer axis which is in good agreement with FEM Model by Sahu and Lu. They attempted to reduce stagnant and dead zones in the flow pattern with blade angle $30,45,60$ and $90^{\circ}$ with respect to the impeller axis. Inactive zone in the cylindrical portion and bottom portion of the crucible are said stagnant zone and dead 
zone respectively $[32,33]$. Also S. Naher, D. Brabazon, L. et al. [34] observed that at $100 \mathrm{rpm}$ and with 0 and 30 degree blade angles no uniform dispersion resulted, but with 45 and 60 degree blade angles there was full particulate dispersion. It is further observed for all stirring speeds that dispersion rates increase with increasing blade angle. The turbine blade also produces dispersion times similar to the best found for the flat bladed stirrers (Naher). They founded the uniform dispersion time for $10 \% \mathrm{SiC}$ particles for different stirrer types and stirring speeds in water of viscosity $1 \mathrm{mPas}$. Whereas no dispersion occurred for the higher viscosity glycerol/water mixtures below $150 \mathrm{rpm}$. it was found that for most cases the 60 degree angle produced the lowest dispersion times. The turbine stirrer again produced the lowest dispersion time. Very similar results were observed for the higher viscosity $(300,500$, 800 and $1000 \mathrm{mPas})$ glycerol/water mixtures tested. High blade angle $\left(\alpha>90^{\circ}\right)$ lead to high level of shearing flow and consume high power as well. Shearing action ensure the solid particle suspension in the melt but without axial suction pressure it is difficult to suck solid particles into the melt. The axial flow can be increased by decreasing the blade angle and significant axial flow was seen close to the liquid surface when the blade angle decreased to $30^{\circ}[32,33,34]$. Moreover, stirring time plays an important role over the distribution of solid particles and power consumption by the stirring motor. Kevin Kurian Paul and Sijo MT [28] reported that the Al-20 wt.\% SiC composite samples by stir casting with 4 Blade Stirrer have high tendency to form particle cluster than 3, and 2 Blade Stirrer due to the homogeneity in mixing Sic additions to the composite which acts as a reinforcement for the aluminium matrix. Also, they confirmed that mechanical properties show greater strength and hardness for four blade stirrers than two blade and five blades. Many researchers $[35,38]$ reported that the increasing vortex height as shown in Fig. 5 depend on stirring speed and viscosities of mixtures. Much greater vortex height observed in high stirring speeds and low mixtures viscosities.

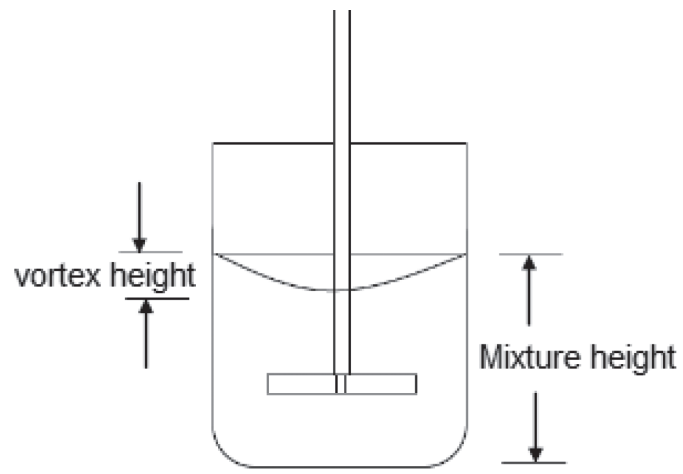

Fig. 5 Vortex and mixture heights

5. ábra Örvény-és keverékmagasság

Skibo et al. [37] proved that vigorously stirring in the melt so as to mix the reinforcement particles incorporated in the melt introduces a greater proportion of gas into the slurry. High velocity of slurry, due to higher stirring speeds forms a vortex on the surface of the slurry. The formation of a vortex on the surface was quite helpful in the movement of ceramic particles into the slurry of alloy and reinforcements. This was attributed to the pressure difference created between the inner and the outer surface of melt, which pulls the ceramic particles into the melt. This has been reiterated by Ghosh and Ray [38] that the extent of porosity in a cast composite depends on the state of agitation and it can be reduced by the control of certain process variables. A vortex created during the stirring can suck the air or gas bubbles in to the liquid metal. As the results, the particles were attached with air bubbles to form the particles cluster in the matrix. At higher temperature $\left(>800{ }^{\circ} \mathrm{C}\right)$, more particles cluster are found in the composite bar [39].

\section{Effect of solidification rate on distribution of particles and porosities in casted CMMCs}

In general, the solidification rate effect on distribution of reinforcement particles, grains size of metals matrix, and porosity which are essential to achieve optimum mechanical properties. The solidification rate is one of the most important factors that affects the reinforcement distribution in composites fabricated by gravity casting and has been investigated in depth both theoretically and experimentally. When the cooling rate is higher than the critical rate, the reinforcement distributes homogeneously in the composite. To improve the properties of composite, should reduce the stirring temperature, and solidify the liquid metal rapidly, or add alloying elements into the matrix alloy [40,41]. Muthazhagan et al. [42] observed by micro structure results of Al-B4C-Graphite composite revealed uniform distribution of reinforcements at a medium cooling rate of solidification whereas solidification at a slow cooling rate resulted in settlement of reinforcement at the bottom of the composite due to density variation of boron carbide, graphite and aluminium. Also, there is enough time for settling down of reinforcement particles at the bottom. Solidification at faster cooling rates resulted in entrapment of particles at the top of the composite. Solidification at faster cooling rates after a homogeneous distribution of the particles in matrix with minimum porosity formation is required to achieve optimum mechanical properties. Also A.Labib et al. [43] reported that the result of $\mathrm{Al} / \mathrm{Si}-10 \mathrm{vol} . \% \mathrm{SiC}$ composite properties are basically controlled by the solidification rate. Higher solidification rates promote homogeneous distribution of the SiC particles. Also M. Makhlouf et al. [44] confirmed that the cooling rate has a marked effect on the grains size, morphology, and distribution of all the microstructural constituents. Increasing cooling rate refines all microstructural features in size, changes the morphology of some reinforcement particles, and decreases the size of all intermetallic compounds regardless of their type. The rate of solidification in $\mathrm{Al} / \mathrm{Si}$ composite depends on a balance between the rate of heat flow from the liquid to the solid through the interface and the latent heat of fusion released during solidification. The thermal conductivities of $\mathrm{Al}$ and $\mathrm{Si}$ in their pure form are 205 and 83 $\mathrm{W} / \mathrm{mK}$ respectively, and their latent heats of fusion are 396 and $1411 \mathrm{~J} / \mathrm{g}$ respectively. Since the difference between the magnitude of the thermal conductivity of pure $\mathrm{Al}$ and pure $\mathrm{Si}$ and the difference between the magnitude of the latent heat of fusion of pure $\mathrm{Al}$ and pure $\mathrm{Si}$ are large, $\mathrm{Al}$ will solidify and shrinkage much faster than Si as shown in Fig. 6(a). 
(a)

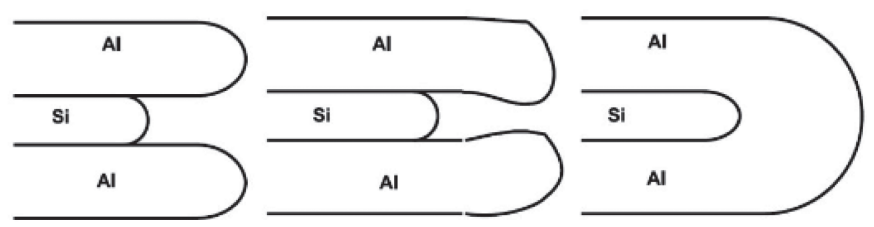

Fig. 6. Solidification in cast Al-Si alloys [53]

6. ábra Al-Si ötvözetek szilárdulási folyamata [53]

By fast cooling the different in cooling rate between $\mathrm{Al}$ and $\mathrm{Si}$ decreased which lead to solidified the Al completely over Si particle as in Fig. 3(b) and (c).

Pradeep Rohatgi et al. [45] also reported that the thermal conductivity and heat diffusivity of particles are generally less than those of the melt, and during the cooling process, the temperature of the particles will be higher than that of the melt. In such cases, it is difficult for the primary phase to nucleate at the particle surfaces. Thermal analysis showed that the unreinforced alloys exhibited undercooling for primary-phase nucleation, whereas the composites generally did not show any significant undercooling. The grain size of the composites is often smaller than that of the unreinforced alloy under identical casting conditions. Solute diffusion is impeded during growth due to the barrier effects of particles [46]. Solidification at faster cooling rates resulted in entrapment of porosity throw-out the composite whereas slow cooling rate form composite with less porosity due to enough time for releasing air bubbles during solidification. Generally, this non uniformity and porosity are generated due to, difference in density between the liquid metal and the reinforcement, oxide skins, and formation of gases. Also, uniform distribution in the matrix with less porosity can be improved by: keep the viscosity within the allowed limit, alloys with minimum reactivity to the reinforcement must be used, covering the melt with an inert gas atmosphere to reduce the oxidation [47].

\section{Effect of reinforcement's weight percentage, particles size and on distribution of particles and porosities in casted CMMCs}

The volume fraction, and particle size also influence the composite particle distribution. Anjan et al. [48] was prepared $\mathrm{Al}-\mathrm{SiC}$ composites containing 5\%,10\% and 15\% weight fractions of silicon carbide particles by stir casting technique. The effects of volume fraction of $\mathrm{SiC}$ particles and its dispersion on the properties of $\mathrm{Al} / \mathrm{SiC}$ composites were investigated. Anjan et al. Reported based on experimental evaluation that tensile strength and hardness were significantly improved by the addition of SiC particles, and clustering of silicon carbide particles in aluminum matrix were observed in microstructure and porosity level increased with increase in SiC Content. Also, Khalid Mahmood [49] Reported that percentage of $\mathrm{SiC}$ should be selected is in line with the information comprehensively reviewed. Also, by using fine particle size, the problem arising from the centrifugal force can also be minimized that produces segregation in the melt due to which the non-uniform properties are attained [50]. By decreasing alumina particle size from micrometer to nanometer, more frequent interactions occur between $\mathrm{Al}$ and hard particles. Moreover, decreasing alumina particle size from micrometer to nanometer led to the reduction of alumina inter-particles distance. Decreasing the distance between alumina particles will increase required tension for dislocation movement between alumina particles and, consequently, enhancement of composite strength [50]. Microstructural analysis of the developed composites indicates that coarse size garnet mineral particles are uniformly distributed in the matrix of LM13 alloy compared to fine size particles. However, particle clustering is observed for fine size reinforced composites [51]. With higher percentage of reinforcements which were stirred for relatively longer time during their processing, have an increased amount of air bubbles sucked into the molten metal vortex. It was found that there is a positive correlation between the particle volume percentage incorporated in a composite and the porosity content of that composite. According to Surrappa [52], in cast metal matrix composites the occurrence of porosity can be attributed invariably to the amount of $\mathrm{H}_{2}$ gas present in the melt, oxide film on the surface of the ceramic particle, which is drawn into the molten metal at the time of stirring. Vigorously stirred melt or vortex tends to entrap gas into the molten mixture. Nripjit et al. [53] also found that the porosity of the reinforced composite is more as compared to unreinforced alloys and goes on increasing with the increase in the volume fraction of the reinforcements in aluminium alloy matrices. In general, with increasing reinforcement weight percentage, and decreasing particles size a significant improvement in the mechanical properties were observed. On the other hand, a sharp reduction in the mechanical properties were observed which was finer particulate and high mass fraction addition level due to high possibility of agglomeration and porosity [54]. Wettability is another significant problem when producing cast metal matrix composites. Wettability can be defined as the ability of a liquid to spread on a solid surface to improve wetting of ceramic particles are:

1. increasing the surface energies of the solid,

2. decreasing the surface tension of the liquid matrix alloy, and

3. decreasing the solid+liquid interfacial energy at the particle matrix interface.

The proper dispersion of reinforcement materials was affected by pouring rate, pouring temperature and gating systems. This paper provides a comprehensive factor that effect on distribution of particles and porosities in casted CMMCs. several authors reported that uniform distribution of the reinforcement particles with less porosity is necessary for the improvement in the properties of MMCs like hardness, toughness, tensile strength etc. [55-58].

\section{Conclusions}

Stir casting is currently the most popular commercial method of producing aluminum-based composites. In this process, powder form as reinforcing phases are usually distributed into molten metal's by mechanical stirring. Nonuniform distribution, and porosity in casted CMMCs consider main disadvantages for stir casting process. 
- During lower speed and lower stir time particle clustering occurred in some places, and some places were identified without inclusion.

- By increasing the stirring speed and stirring time better homogeneous distribution of $\mathrm{SiC}$ in the $\mathrm{Al}$ matrix were found.

- At higher stirring speed of $700 \mathrm{rpm}$, the porosity in the microstructure is more pronounced. This condition is attributed to the vigorous vortex formation due to high stirring speed which enables oxide skins, gases and contaminants to be entrained in the melt.

- Optimum stirring speed and time are required in order to achieve uniform distribution in the matrix with less porosity. Also uniform distribution in the matrix with less porosity can be improved by: keep the viscosity within the allowed limit, alloys with minimum reactivity to the reinforcement must be used, covering the melt with an inert gas atmosphere to reduce the oxidation, giving heat treatment to the reinforcement particles to remove gas layer around the particle surface which impedes wetting between the particles and molten metal's, and stirring of the melt to minimize the settling of particles due to density difference.

- Selection of a suitable blade angle, and numbers of blades are crucial to acquire good level of axial flow and shearing action.

- With 45- and 60-degree blade angles there was full particulate dispersion. It is further observed for all stirring speeds that dispersion rates increase with increasing blade angle.

- Dispersion rates increase with increasing blade angle, whereas no dispersion occurred for the higher viscosity glycerol/water mixtures below $150 \mathrm{rpm}$.

- Most cases the 60-degree angle produced the lowest dispersion times.

- High blade angle $\left(\alpha>90^{\circ}\right)$ lead to high level of shearing flow and consume high power as well. Shearing action ensure the solid particle suspension in the melt but without axial suction pressure it is difficult to suck solid particles into the melt.

- The axial flow can be increased by decreasing the blade angle and significant axial flow was seen close to the liquid surface when the blade angle decreased to $30^{\circ}[39,40,41]$.

- Solidification at faster cooling rates after a homogeneous distribution of the particles in matrix with minimum porosity formation is required to achieve optimum mechanical properties.

- Solidification at faster cooling rates resulted in entrapment of particles at the top of the composite in some cases.

- Solidification at faster cooling rates resulted in entrapment of porosity throw-out the composite whereas slow cooling rate form composite with less porosity due to density and the enough time for releasing air bubbles during solidification.

- Solidification at a slow cooling rate resulted in settlement of reinforcement at the bottom of the composite due to density variation of boron carbide, graphite and aluminium.
- With increasing reinforcement weight percentage, and decreasing particles size a significant improvement in the mechanical properties were observed. On the other hand, a sharp reduction in the mechanical properties were observed which was finer particulate and high mass fraction addition level due to high possibility of agglomeration and porosity.

References

[1] Maha, S. H. 2017. Composites Classification and Manufacturing Operations: A Review. International Journal of Advance Research 3:1708- 1713.

[2] Ratan, K., K. S. Er.Sushil. 2018. Thermal Property Evaluation of Heat Treated Aluminium Metal Matrix Composite Material. International Journal of Engineering Development and Research 6:2321-9939. https://www.ijedr.org/papers/IJEDR1801033.

[3] Pradeep, K. S., J. Satheesh. 2018. A Study on Tensile, Hardness, and Impact Strength using Al7075as Matrix Material and by using different Reinforcement: A Review. International Research Journal of Engineering and Technology 07: 2395-0056. https://doi.org. t/archives/V5/i7/IRJET-V5I7166.

[4] Ali, M., F. Samer. 2014. Synthesis and Characterization of Aluminum Composites Materials Reinforced with TiC Nano- Particles. Jordan Journal of Mechanical and Industrial Engineering 8:244-250. http://jjmie.hu.edu.jo/vol\%2010-4/JJMIE-2016-10-4.

[5] Bahrami, A., N. Soltani, M.I. Pech-Canul, C. A. Gutiérrez. 2015. Development of metal-matrix composites from industrial/agricultural waste materials and their derivatives. critical reviews in environmental science and technology 1:166. https://doi.org/10.1080/10643389.2015.1077067.

[6] Skolianos, S. 1996. Mechanical Behavior of Cast SiC p-Reinforced Al4.5\% Cu-1.5\%Mg Alloy. Materials Science and Engineering 210:76-82. https://doi.org/10.1016/0921-5093(95)10043-1

[7] GLOWSKI, M. S., A.WRONA, I. NEJMAN, M. RICHERT. 2018. Microstructural evaluation of Re particle reinforced composite on aluminium surface by friction stir processing. Journal of Silicate Based and Composite Materials 70:181-185. https://doi.org/10.14382/epitoanyag-jsbcm.2018.32

[8] Sergey, N., Svetlana P. BUYAKOVA, Maria CHATZINIKOLAIDOU. 2015. Rheology and porosity effect on mechanical properties of zirconia ceramics. Journal of Silicate Based and Composite Materials 67:150-158. https://doi.org/10.14382/epitoanyag-jsbcm.2015.26

[9] Ahmad, S. N. A. S., J. Hashim, M. I. Ghazali. 2007. Effect of Porosity on Tensile Properties of Cast Particle Reinforced MMC. Journal of Composite Materials 41:575-589. https://doi.org/10.1177/0021998306066720

[10] Madhav Reddy S., A. Chennakesava Reddy. 2006. Effects of Porosity on Mechanical Properties of Zirconium Oxide/AA1100 Alloy Metal Matrix Composites. National Conference on Materials and Manufacturing Processes 2:124-128. https://jntuhceh.ac.in/web/tutorials/faculty/1318_TiO-6061.

[11] Vemula, V. V., Sanjay K. C.2018. The effect of process parameters in Aluminum Metal Matrix Composites with Powder Metallurgy. Manufacturing 5:13. https://doi.10.1051/mfreview/2018001

[12] J. Wiley \& Sons, “Technology \& Engineering - Handbook of Composite Reinforcements “, P 344-355, 30-Nov-1992.

[13] Calin, R., M. Pul, and Z. Pehlivanli. 2012. The Effect of Reinforcement Volume Ratio on Porosity and Thermal Conductivity in Al-Mgo Composites. Materials Research 15:1057-1063. https://doi.org/10.1590/s1516-14392012005000131

[14] Prabu, S. B., L. Karunamoorthy, S.Kathiresan, B. Mohan. 2006. Influence of stirring speed and stirring time on distribution of particles in cast metal matrix composite. Journal of Materials Processing Technology 171:268-273. https://doi.org/10.1016/j.jmatprotec.2005.06.071

[15] Adetayo, A., Adebisi, M. Abdul, B. N. Mohammed. 2017. Influence of Stirring Speed on Microstructure and Wear Morphology of SiCp$6061 \mathrm{Al}$ Composite. International Journal of Engineering Materials and Manufacture 1:21-26. https://doi.org/10.26776/ijemm.01.01.2016.05

[16] Aqida, S.N., M.I. Ghazali, J. Hashim .2003. The Effects Of Stirring Speed and Reinforcement Particles on Porosity Formation in Cast MMC. Journal Mechanical 16:22-30. https://doi.org/10.11113/jt.v40.395

[17] Hashim, J., Looney L, M.S.J. Hashmi. 1999. Metal matrix composite Production by the stir casting method. Journal of Materials Processing Technology 92:1-7. https://doi.org/10.1016/s0924-0136(99)00118-1

[18] Davis, J., Aluminum and Aluminum Alloys. Technology \& Engineering, Handbook, P 164, 1993 
[19] Rana, R. S., P. Rajesh. 2012. Review of recent Studies in Al matrix composites. International Journal of Scientific \& Engineering Research 3:2229-5518. https://doi.org/www.ijser.org/researchpaper.

[20] Vaibhav, I., S. Madhukar. 2017. Defects, Root Causes in Casting Process and Their Remedies: Review. Int. Journal of Engineering Research and Application 3:47-54. https://doi.org/10.9790/9622-0703034754

[21] Hashim, J. 1999. Microstructure and Porosity Studies of Cast Al-SiCp Metal Matrix Composite. Jurnal Teknologi. 31:1-12.

[22] Sajjadi, S. A., H. R. Ezatpour, H. Beygi. 2001. Microstructure and mechanical properties of $\mathrm{Al}-\mathrm{Al}_{2} \mathrm{O}_{3}$ micro and nano composites fabricated by stir casting. Materials Science and Engineering A 528:8765-8771. https://doi.org/10.1016/j.msea.2011.08.052

[23] Ratna, B. S., G. Pradeep, R. Kumar, P. Hemendra, D. Ravikumar. 2016. Magnesium Based Surface Metal Matrix Composites by Friction Stir Processing. Journal of Magnesium and Alloys 4:52-61. https://doi.org/10.1016/j.jma.2016.02.001

[24] Amouri, K., Sh. Kazemi , A. Momeni, M. Kazazi. 2016. Microstructure and Mechanical Properties of Al- nano/micro SiC Composites Produced by Stir Casting Technique. Materials Science \& Engineering A 674:569578. https://doi.org/10.1016/j.msea.2016.08.027

[25] Yu, W., X. Wang, H. Zhao, C. Ding, Z. Huang, H. Zhai, Z. Guo, S. Xiong. 2017. Microstructure, Mechanical Properties and Fracture Mechanism of $\mathrm{Ti}_{2} \mathrm{AlC}$ Reinforced AZ91D Composites Fabricated by Stir Casting\|. Journal of Alloys and Compounds 702:199-208. https://doi.org/10.1016/j.jallcom.2017.01.231

[26] Marinho, R., L. Horiuchi, C. P. Augusto. 2018. Effect of stirring speed on conversion and time to particle stabilization of poly (vinyl chloride) produced by suspension polymerization process at the beginning of reaction. Brazilian Journal of Chemical Engineering 35:631-640. https://doi.org/10.1590/0104-6632.20180352s20160453

[27] Jailani, A., S.M. Tajuddin. 2012. Mechanical Properties of Stirred SiC Reinforced Aluminium Alloy: Stir Casting With Different Composition of SiC, Blade Angle and Stirring Speed. Advanced Materials 622-623:13351339. https://doi.org/10.4028/www.scientific.net/amr.622-623.1335

[28] Paul, K. K., MT. Sijo. 2015. Effect of Stirrer Parameter of Stir casting on Mechanical Properties of Aluminium Silicon Carbide Composite. International Journal Of Modern Engineering Research (IJMER), 5:43-49. https://archive.org/stream/Httpijmer.

[29] Jokhio, M. h., Muhammad ibrahim panhwar, Mukhtiar ali unar. 2011. Manufacturing of aluminum composite material using stircasting process. Mehran university research journal of engineering \& technology 30:53-64.

[30] Bihari, B., A. K. Singh. 2017. An Ove rview on Different Processing Parameters in Particulate Reinforced Metal Matrix Composite Fabricated by Stir Casting Process Preparation of Aluminium Matrix Composite by Using Stir Casting Method. Int. Journal of Engineering Research and Application 7:42-48. https://doi.org/10.9790/9622-0701034248

[31] Ravi, KR., V.M. Sreekumar, RM. Pillai. 2005. Optimization of mixing parameters through a water model for metal matrix composites synthesis. Materials and Design 28:871- 881. https://doi.org/10.1016/j.matdes.2005.10.007.

[32] Lu, J., Z. Lu. 2010. Optimization of stirring parameters through numerical simulation for the preparation of aluminum matrix composite by stir casting process. Journal of Manufacturing Science and Engineering 132:17. https://doi.org/10.1115/1.4002851

[33] Sahu, MK., RK. Sahu. 2017. Optimization of stirring parameters using CFD simulations for HAMCs synthesis by stir casting process. Transactions of the Indian Institute of Metals.70:2563-2570. https://doi.org/10.1007/s12666-017-1119-5

[34] Naher, S., D. Brabazon, L. Looney. 2003. Simulation of the stir casting process. Journal of Materials Processing Technology 143:567-571. https://doi.org/10.1016/s0924-0136(03)00368-6

[35] Rajavathsavai, D., A. Khapre, B. Munshi. 2014. Numerical Study of Vortex Formation inside a Stirred Tank. international Journal of Chemical, Molecular, Nuclear, Materials and Metallurgical Engineering 8: 1421-1426.

[36] Devi, T., B.Kumar. 2017. Vortex depth analysis in an unbaffled stirred tank with concave blade impeller. Chem. Technol.11:301-307. https://doi.org/10.23939/chcht11.03.301

[37] Skibo, M., P.L.Morris, D.J. Lloyd. 1988. Structure and properties of liquid metal proceeded $\mathrm{SiC}$ reinforced aluminum", Cast reinforced metal composites. Materials Park, OH: ASM International :257-261.

[38] Ghosh, P.K, S. Ray. 1988. Porosity in a cast composite. Indian J.Technol., 26:83

[39] Bharath, V., Madev Nagaral, V Auradi, S. A. Kori.2014. Preparation of 6061Al-Al2O3 MMC's by Stir Casting and Evaluation of Mechanical and
Wear Properties. Procedia Materials Science 6: 1658 - 1667.

https://doi.org/10.1016/j.mspro.2014.07.151

[40] Singh, A., ID. Yoshiaki Osawa, H. Somekawa, T. Mukai. 2018. Effect of Solidification Cooling Rate on Microstructure and Mechanical Properties of an Extruded Mg-Zn-Y Alloy. Metals 8:337. https://doi.org/10.3390/met8050337

[41] Liang, G., Y. Ali, G. You, Ming, X. Zhang. 2018. Effect of cooling rate on grain reinforcement of cast aluminium alloys. Materialia, 3:113-121. https://doi.org/10.1016/j.mtla.2018.08.008

[42] Muthazhagan, C., K. Rajkumar. 2015. Effect of Cooling Rate on Distribution of Boron Carbide and Graphite in Al 6061 Composites During Solidification. International Journal of Applied Engineering Research 10:1429-1433.

[43] Labib, A., H. Liu, F.H. Samuel. 1993. Effect of solidification rate $\left(0.1-100^{\circ} \mathrm{C}\right.$ $\mathrm{s}-1)$ on the microstructure, mechanical properties and fractography of two AlSi-10vol.\%SiC particle composite castings. Materials Science and Engineering 160:181-90. https://doi.org/10.1016/0921-5093(93)90500-e

[44] Makhlouf, M.M. and H.V. Guthy. 2001. The Al-Si Eutectic Reaction: Mechanisms and Crystallography. J. Light Metals 1:199-218. https://doi.org/10.1016/s1471-5317(02)00003-2

[45] Rohatgi, P. B. Schultz. 2008. Solidification During Casting of MetalMatrix Composites. ASM Handbook, Volume 15: Casting, Pages 390-397. https://doi.org/10.31399/asm.hb.v15.a0005227

[46] Liu, Y., P.K. Rohatgi, S. Ray. 2008. Characteristics of Aluminum-50 volpct Graphite Composite,Metall. Mater.Trans. A 24:151-159. https://doi.org/10.1007/bf02669612

[47] Amouri, K., Sh. Kazemi, A. Momeni, M. Kazazi. 2016. Microstructure and Mechanical Properties of Al- nano/micro SiC CompositesProduced by Stir Casting Technique. Materials Science \& Engineering A. 674:569 578. https://doi.org/10.1016/j.msea.2016.08.027

[48] Ajago, P., B. N. Anjan, R. N. Marigoudar, G. V. Preetham Kumar. 2018. Effect of $\mathrm{SiC}$ Reinforcement on Microstructure and Mechanical Properties of Aluminum Metal Matrix Composite. IOP Conf. Series: Materials Science and Engineering 376:012057. https://doi.org/10.1088/1757-899x/376/1/012057

[49] Ghauri, K. M., L. Ali, A. Ahmad, R. Ahmad, K. M. Din, I. A. Chaudhary, R. A. Karim. 2013. Synthesis and Characterization of $\mathrm{Al} / \mathrm{SiC}$ Composite Made by Stir. Pak. J. Engg. \& Appl. Sci.12:102-110

[50] Tahamtan, S., M. Emamy, A. Halvaee. 2014. Effects of reinforcing particle size and interface bonding strength on tensile properties and fracture behavior of Al-A206/alumina micro/nano composites . Journal of Composite Materials 48: 3331. https://doi.org/10.1177/0021998313509860

[51] Sharma, A., S. Kumara, , R. Arorab, O.P. Pandeyc. 2015. Effect of Particle Size on Wear Behavior of Al-Garnet Composites. Journal Particulate Science and Technology 33: 234-239. https://doi.org/10.1080/02726351.2014.954686

[52] Surrappa, M.K. 1997. J. Mater. Process. Technol. 63:325

[53] Nripjit, A.K., Tyagi, N.Singh, A.Singh.2007. Advancesin Applied research 4:240.

[54] Yehia, M., Youssef, M. A. El-Sayed. 2016. Effect of Reinforcement Particle Size and Weight Fraction on the Mechanical Properties of SiC Particle Reinforced Al Metal Matrix Composites. International Review of Mechanical Engineering 10:1970 - 8734. https://doi.org/10.15866/ireme.v10i4.9509

[55] Clyne, T. W. 1996. Physical Metallurgy: Metallic Composite Materials UK: Elsevier Science

[56] Whitehouse, A. F. 2000. Creep of Metal Matrix Composites. Comprehensive Composite Materials 3:371-418. https://doi.org/10.1016/ b0-08-042993-9/00014-0

[57] Skolianos, S. 1996. Mechanical Behavior of Cast SiC p-Reinforced Al4.5\% Cu-1.5\%Mg Alloy. Materials Science and Engineering: A 210:276-82. https://doi.org/10.1016/0921-5093(95)10043-1

[58] Jung, A., H. J. Maier, H. J. Christ. 2000. High-Temperature Fatigue Behaviour and Microstructure of a Dispersoid-Strengthened and SiCReinforced Aluminium Alloy. Microstructure and mechanical properties of metallic high-temperature materials: 34-49. https://doi.org/10.1520/stp15260s

Ref.:

Ali, Malek: Review of stir casting technique and technical challenges for ceramic reinforcement particulate and aluminium matrix composites

Építőanyag - Journal of Silicate Based and Composite Materials, Vol. 72, No. 6 (2020), 198-204. p. https://doi.org/10.14382/epitoanyag-jsbcm.2020.32 